\title{
Study of Cotton Costs Income and Subsidy Policy in Xinjiang Xiaoyong $\mathrm{Li}^{1, \text { a }}$, Yuan $\mathrm{Xu}^{2, \mathrm{~b}}$, Qiong $\mathrm{Ma}^{3, \mathrm{C}}$ \\ 1,3 Tarim University, Alar, Xinjiang, 843100 \\ ${ }^{2}$ Xinjiang University, Aksu, Xinjiang, 843000 \\ ${ }^{a}$ email, ${ }^{b}$ email, ${ }^{c}$ email
}

\section{Keywords: Xinjiang, Cotton, Costs and Income, Subsidy Policy}

\begin{abstract}
Xinjiang Corps is a major producer of cotton, the cotton industry development is not only related to the growth of the agricultural economy in Xinjiang, but also directly affects the increase of farmers' income. However, due to the slowdown in the growth rate of textile and rising agricultural prices, cotton planting costs is increasing. It greatly affected the income of farmers and the development of the cotton industry. Subsidies is a major strategy for its development of Xinjiang Corps cotton industry and it has a very important role, in order to better improve the Corps of Xinjiang cotton subsidies mechanism, this paper analyzes cotton cost-benefit of Xinjiang, made several recommendations to improve cotton subsidies, but also hope that through this investigate we can promote the development of Xinjiang cotton industry and cotton farmers planted improve economic benefits.
\end{abstract}

\section{Introduction}

Xinjiang cotton is a pillar industry, which not only occupy a pivotal role in the development of agricultural economy in Xinjiang, their livelihoods and for the development of the textile industry in Xinjiang farmers have a direct impact. By 2014, Xinjiang cotton output accounted for 73\% of China's cotton production, but also accounted for $18 \%$ of global cotton production, at the same time the Xinjiang $50 \%$ of the population engaged in cotton, cotton industry revenue accounted for farmers how one-third of income, we can see how important it is for Xinjiang cotton farmers, however, from the current situation in Xinjiang cotton production, the impact of cotton production costs increase and other issues, making cotton income households decreased, affecting the growth of the agricultural economy in Xinjiang. Subsidies are state support Xinjiang cotton industry is a major strategy for the promotion of their agricultural development in Xinjiang has great significance. Cotton Production in Xinjiang Corps as one of the main producer of cotton subsidies Xinjiang Corps to study a very important role in a typical representative. Therefore, we focused on the cost-effectiveness of cotton in Xinjiang Corps conducted analysis and research, hoping to explore a more scientific and rational subsidy policy, to better promote the development of Xinjiang cotton industry to bring greater economic benefits for farmers in Xinjiang.

\section{The Current Situation in Xinjiang}

Corps as an important cotton cultivation, cotton yields far higher than its average level of China and the world. Corps total cotton acreage accounted for about $60 \%$ of farming, the dominant role determines its importance for the agricultural economy. However, in recent years due to the means of production, tractor costs and labor costs, making the cotton-growing cost of rapid growth, coupled with the slowdown in textile exports increase, natural disasters occur frequently and are greatly hampering the economic benefits of cotton in Xinjiang Corps. The Government has always attached great importance to the cultivation of cotton in Xinjiang Corps to support the work, in order to ensure sustainable development of cotton, bring considerable economic benefits for farmers, subsidies as a government to support a large work, which play in the Xinjiang Corps increase in cotton a very important role, however, China's cotton subsidies due to the development and implementation of practice is relatively short, the implementation of lack of experience, judgment 
based on the lack of effective legal protection, the combined effect of subsidies need to be further evaluated and improved.

\section{The Need to Improve the Mechanism of Cotton Subsidies}

China as the world's most populous country, and which continues to increase, with the increasing population, people's living standards improve, we inevitably increases the demand for cotton. However, in the case of land does not increase, as the main origin of cotton in Xinjiang, the Corps as a major producer of cotton, the inevitable need to take more responsibility for production. Corps is to promote the development of the cotton industry through subsidies, only to meet the growing domestic demand for cotton.

With the continuous development of agriculture, implementation of many areas in Xinjiang by the fruit, add grain, reduce cotton, cotton acreage is beginning to show-by see a downward trend. Data show that Xinjiang Corps cotton acreage in recent years also showed a declining trend. In this case I, improve the policy of the Corps of cotton, can effectively reduce the cost of investment in cotton, cotton farmers to avoid planting initiative to improve to meet the needs of agricultural industry structure optimization.

All along, China attaches great importance to high-quality cotton, grain, horticulture and animal husbandry base characteristics of Xinjiang and the construction and development, but also attaches great importance to the construction of Xinjiang agricultural modernization. At present, Xinjiang is in the best opportunity of modernization, so the development of Xinjiang Corps cotton, grain compensation policy, not only to guarantee a stable supply of cotton and other agricultural products, as well as the basic premise of modern agricultural development.

Xinjiang Corps is the main cotton producing areas of Xinjiang cotton, which occupies a large part of the Cotton Industry. However, due to various reasons of history, geography and traditional industries, regions corps exhibit secondary and tertiary industries underdeveloped phenomenon in cotton autonomous acquisition and processing capabilities are relatively weak, so more cotton for export. By improving the compensation mechanism Corps, so that not only can mobilize the enthusiasm of farmers in cotton, but also promote and Construction Corps water projects through subsidies, the transformation of low-yielding fields, farmland shelterbelt construction of large farm machinery and inputs in order to protect the cotton external stable supply.

\section{The Cost-Benefit Analysis of Cotton}

Agricultural production costs as part of the value of agricultural products, which mainly include the production of agricultural products consumed in the process of production (such as seeds, fertilizer, farm machinery depreciation due to the production and management services for the production of a series of charges) and labor consumption cost costs Sum. On the cost of production of cotton, its cost items including material costs and the cost of labor and employment of these two inputs. Material costs include fees seeds, manure costs, fertilizer costs, costs of plastic film, pesticides fees, animal costs, machinery operating costs, irrigation fees, fees can be directly included in a series of direct production costs of cotton crop production, as well as fixed assets depreciation, initial production costs, small farm implements acquisition costs, management fees and other expenses, marketing costs and a series of cotton and other crops, and would need to go through assessments included in the cost of the indirect production costs. In labor and employment costs, which also include pre-planting plowing soil preparation labor, seed preparation and planting labor (including nursery and seedling management labor), fertilization labor, irrigation and drainage employment, field management and labor (including weeding, to fight drugs and pest control, care crop employment ), harvest labor (including income play storage), primary processing labor, other direct production labor and other direct production of a series of labor costs, and initial production and employment assessments, manure labor, management and employment, volunteer work and accumulation, sales and employment other indirect employment and a series of indirect labor costs. 


\section{The Idea of Cotton Subsidies Cost-Benefit Analysis}

I believe that cotton subsidies improve the general idea should be to increase investment in cotton, cotton production to reduce costs and increase cotton subsidy programs, improve efficiency and standardize subsidies and allowances. Increase investment in water conservancy construction means for increasing cotton production, cotton production and the development and utilization of farmland into groundwater and other aspects of security corps cotton acreage. Reduce the cost of cotton production on the one hand refers to the scientific and reasonable production inputs for optimal allocation of production factors, to achieve maximum economic benefits. On the other hand it refers mechanized cotton picker and other emerging technologies to reduce labor intensity, reduce the cost of artificial cotton and other production costs, thereby enhancing the productivity of cotton. Increase in cotton subsidy program refers to the existing foundation and analyze the factors affecting the production of cotton production benefits, subsidies to develop appropriate strategies. Improve the efficiency of the implementation of subsidies for subsidies to slow the situation, one reason is that subsidies to carry out slow, and secondly, the next subsidy payments made slowly. Subsidies work is due to subsidies to training and supervision is not enough, many grassroots cadre lack of experience in the implementation of subsidies work.

\section{Xinjiang Cotton Subsidies Specific Recommendations}

Cotton has been an important part of the income of cotton household income, but rising costs of cotton production, cotton sales slow down, earnings cotton households began to decline in the phenomenon. Cotton sales slowed for the case to determine a reasonable minimum price of cotton, farmers sell low subsidy. This will not only be able to safeguard cotton household income, but also to better stimulate the enthusiasm of farmers to plant cotton.

Establish and improve the cotton fund risk refers to the government for special funds to economic regulation Cotton manner to changes in market prices of cotton, cotton circulation changes in the established order. Therefore, in order to guarantee the smooth implementation of the subsidy policy, the primary task of establishing a risk fund and improvement of cotton by the government unified arrangement according to cost-effectiveness of the Corps of cotton, cotton farmers for production subsidies, interest subsidies quality cotton base construction loans and cotton sales circulation subsidies. Ensure there is sufficient funding for the Corps of cotton subsidies.

All along, Xinjiang Corps are natural disaster-prone areas, natural disasters often result in lower cotton production efficiency. Therefore, strengthening cotton natural disasters subsidy mechanism, the Government established policy cotton mechanisms to address damage caused by natural disasters on farmers caused to bear the cost of subsidies for cotton by the government, such as the purchase of insurance for farmers with subsidy payments, reduce the losses of farmers due to natural disasters caused by further improve cotton farmers' enthusiasm.

Government in the past mainly directs subsidies to cotton subsidies that the government on agricultural production, circulation and business conduct of transfers of cotton subsidies. Although in the past for a long period of time with great success, but with the Xinjiang development of urbanization, the rural labor force showed a downward trend, the production of which the contribution of cotton grower is increasingly apparent. Therefore, a sound system of subsidies for cotton production of large, one can increase the cotton production of large cotton growing enthusiasm, and secondly better drive small farmers to large cotton production target.

Inclusive finance refers to banks and other financial institutions primarily for low-income groups to provide adapted financial services for low-income people to provide more favorable financial services, to solve their difficulties in production and cultivation, relying on their own ability to get rid of poverty. Currently, the lack of funding agricultural production phenomenon is mainly low-income farmers, relying on government funding subsidies, improve the rural financial service Pratt \& Whitney, which on the one hand to promote the standardized management of new rural financial institutions, on the other hand in rural Pratt \& Whitney financial support and support services, the better to drive the healthy development of Xinjiang cotton industry. 
Grassroots cadres, as the direct perpetrators of the subsidy policy implementation, its efficiency will directly affect the efficiency of the cotton subsidies policy implementation. However, the current due to some grassroots cadre awareness of cotton subsidies are not in place, so that the implementation of the subsidy policy is not in place. Therefore, we must strengthen the awareness of cotton subsidies grassroots cadres, increase the training of grassroots cadres, the establishment of regulatory subsidies, subsidies to implement safeguards in place, subsidies work smoothly.

\section{Conclusion}

Xinjiang, as the main producer of cotton and guarantee rapid and stable development of relations cotton to Xinjiang Agricultural Economic Growth. As China's agricultural subsidies to support a major initiative for the development of Xinjiang Corps its cotton industry, farmers' income has a very important practical significance. Therefore, we must work to implement good cotton subsidies for Xinjiang Corps to establish cotton household income security system, improve risk control fund cotton, natural disasters subsidy mechanism to strengthen and improve the production of large subsidies, improve the rural inclusive financial services and strengthen grassroots cadres subsidies intended to ensure that subsidies can bring rapid development of Xinjiang cotton industry and cotton cultivation to increase farmers income.

\section{References}

[1] Tian Liwen, Bai Hebin, Bo Chaohua, Cui Jianping, Wan Huiping. Cotton subsidies, problems and countermeasures exists[J].. Xinjiang Agricultural Sciences, 2015 (07).

[2] Mao Shuchun. Target price subsidies on cotton in questions, comments and suggestions [J]. Chinese economy Fluid Circulation, 2014 (03).

[3] Huo Yuan. Cotton and cost-effective compensation mechanism research [D]. Xinjiang Agricultural University, 2011.

[4] Li Wenchun. On the development strategy of Xinjiang Corps cotton industry [J]. Hubei Agricultural Mechanization, 2012 (06).

[5] Wang Li, Zhang Jie, Zhao Xinmin, Jia Juanqi. plight faced by the cotton industry in Xinjiang and Countermeasures [J]. Economic Space Reclamation, 2012 (11).

[6] Zhang Jie, Du Min. Investigation of the effect implemented. Cotton target price subsidies [J]. Agricultural Economy, 2016 (02).

[7] Wang Li, Wen Ya. Measures and Effects of Xinjiang cotton target price subsidy policy analysis [J]. Prices Monthly, 2015 (09).

[8] Ma Qiong, Liu Wencun, Liu Qinqin, Wang Yapeng. cotton production complex outside of non-market valuation - based on the cotton subsidies Perspective [J]. Cotton Science, 2013 (02).

[9] Jia Zhitang, Zhang Long, Zhang Jun. Cotton subsidies on cotton industry change - A Case Study of Aksu Prefecture [J]. Financial Development Review, 2015 (05). 